\title{
PROSTHOPORUS, A NEW BOLIVIAN GENUS OF THE SUBTRIBE LYMEONINA (HYMENOPTERA, ICHNEUMONIDAE)
}

\author{
By Charles C. PORTER ${ }^{1}$ \\ Department of Biological Sciences \\ Fordham University, Bronx, N.Y. 10458, U.S.A.
}

Since 1973 I have been conducting a Malaise Trap survey of Hymenoptera at the Bolivian government's Agricultural Experiment Station near General Saavedra in the Department of Santa Cruz. Ing. Oscar Terán and Ing. José Rocavado of the Comisión Nacional del Estudio de la Caña y del Azucar generously pointed out a protected remnant of subtropical wet forest for safe installation of my traps and have supervised retrieval of samples at monthly intervals. The Committee for Research and Exploration of the National Geographic Society awarded grants for the summers of 1973-'75 which covered travel and equipment expenditures incurred during this project. More recently, a U.S. National Science Foundation Grant (No. DEB 75-22426) has provided funds for technical assistance in sorting and preparation of the thousands of Hymenoptera so far accumulated by the trap survey.

I have completed identification of the ichneumonids trapped at General Saavedra during 1973-'74 and among this material find a remarkable new genus belonging to the Subtribe Lymeonina of the Tribe Mesostenini. This genus now is described so as to make it available for inclusion in a phaenologic and biogeographic study of the Saavedra ichneumonid fauna which I am preparing for publication at a later date.

\section{Prosthoporus new genus}

Length of fore wing: $9.0 \mathrm{~mm}$. Body: slender. Front: without a median horn or carina, smooth and shining wth some weak shagreening. Clypeus: moderately large, in profile basad gently convex with highest point a little before middle and apicad flattened to slightly concave and without a median tooth or tubercle.

${ }^{1}$ Research Associate, Florida State Collection of Arthropods, Florida Department of Agriculture and Consumer Services, Gainesville, Florida.

Manuscript received by the editor February' 10, 1977. 
Mandible: 2.5 as long as wide at middle, lower tooth strong but distinctly shorter than upper tooth. Temple: in dorsal view flat and abruptly receding, in profile at its upper 0.3 about 0.21 as long as eye. Occipital carina: gently curved, fading out below a short distance before joining hypostomal carina. Malar space: 0.40 as long as basal width of mandible. Pronotum: upper margin weakly swollen; epomia only weakly suggested. Notaulus: fine and sharp, reaching 0.4 the length of mesoscutum. Mesopleural fovea: in the form of an isolated shallow pit located well in front of mesopleural suture and not connected to it by a horizontal groove. Sternaulus: very weak and shallow, faintly traceable for about half the distance to middle coxa. Postpectal carina: defined only for a short distance laterad, its median section absent. Metanotum: its hind margin without a projection on each side of postscutellum, the part below the hind margin long, gently sloping, and not wrinkled. Propodeum: elongate, gently and evenly arched in profile and without a sharply discrete apical face; spiracle short-oval, 2.0 as long as wide; basal trans-carina sharp throughout and practically straight; no apical trans-carina or cristae; entire surface behind basal trans-carina covered with dense, regular transverse wrinkles which are finer basad and coarser apicad. Hind coxa: its base shallow with a short horizontal groove next to attachment. Front tibia: in female moderately swollen and with some unusually strong, sparse spine-like setae in addition to the normal dense vestiture of fine setae. Front tarsus: in female with fourth segment deeply bilobed at apex. Wing venation: areolet moderately large, rectangular and nearly parallel-sided, about 0.6 as high as section of second recurrent vein above bulla, about 1.7 as wide as high, receiving second recurrent vein well before middle; second intercubitus weak and medially effaced; ramellus absent; postnervulus intercepted at its upper 0.25; nervulus 0.3 its length antefurcal; nervellus intercepted at its upper 0.4 ; apical half of mediella strongly arched; brachiella absent; axillus close to hind margin of wing and converging to hind margin apically. First gastric segment: elongate and almost parallel-sided; its spiracle situated definitely in front of the middle at about basal 0.39 of tergite; without a lateral tooth at base; without longitudinal carinae, except for basal vestiges of the dorso-lateral carinae; postpetiole 0.58 as wide apically as long from spiracle to apex; apex of first sternite far distad of spira- 
cle, at a point about 0.5 the distance between spiracle and apex of tergite. Second gastric tergite: thyridium subcircular; surface with short, sparse setae. Ovipositor: sheathed portion 0.94 as long as hind tibia; slender, moderately compressed; dorsal valve on tip smooth, without notch or nodus; ventral valve on tip with very strong, inclivously oblique to vertical ridges and produced into a lobe that partially encloses the upper valve.

TYPE SPECIES: Prosthoporus terani new species.

DISCUSSION: Prosthoporus may be separated from all other genera of the Tribe Mesostenini by the following combination of characters: occipital carina terminates below a little before hypostomal carina; sternaulus faint and only traceable on basal half of mesopleuron; whole propodeum behind basal trans-carina with regular transverse striae; areolet rectangular, 1.7 as wide as high; brachiella absent; first gastric tergite elongate, parallelsided, and with spiracle situated at basal 0.39; ventral valve of ovipositor partly overlaps dorsal valve on tip. The position of the first tergite spiracle is unusual. Most Mesostenini have this spiracle behind the middle of the tergite while only a few have it at or slightly before the middle. In Prosthoporus the spiracle is located farther basad than in any other mesostenine genus known to me.

Townes (1969, p. 141-145) provides a tentative subtribal classification of the mesostenines. Within his framework, Prosthoporus shows affinity to the Subtribe Gabuniina in position of the first tergite spiracle, structure of the ovipositor tip, and in the somewhat inflated female front tibia. However, the foregoing are adaptive characters possessed independently by numerous Mesostenini that parasitize wood boring beetle larvae and Prosthoporus differs substantially from the Gabuniina by having the lower mandibular tooth shorter than the upper and by its deeply bilobed female fourth front tarsomere. Otherwise, Prosthoporus runs easily in Townes' subtribal key to couplet 17 which differentiates between the Lymeonina and Ceratocryptina. Here it will go unequivocally to neither subtribe as now defined but agrees with the Lymeonina in most features except for the rectangular areolet which is "much wider than high" as in Ceratocryptina. For the present, I consider Prosthoporus a lymeonine but agree with Townes (1969, p. 141) that some of the currently recognized subtribes of Mesostenini "are doubtless partly artificial and even- 

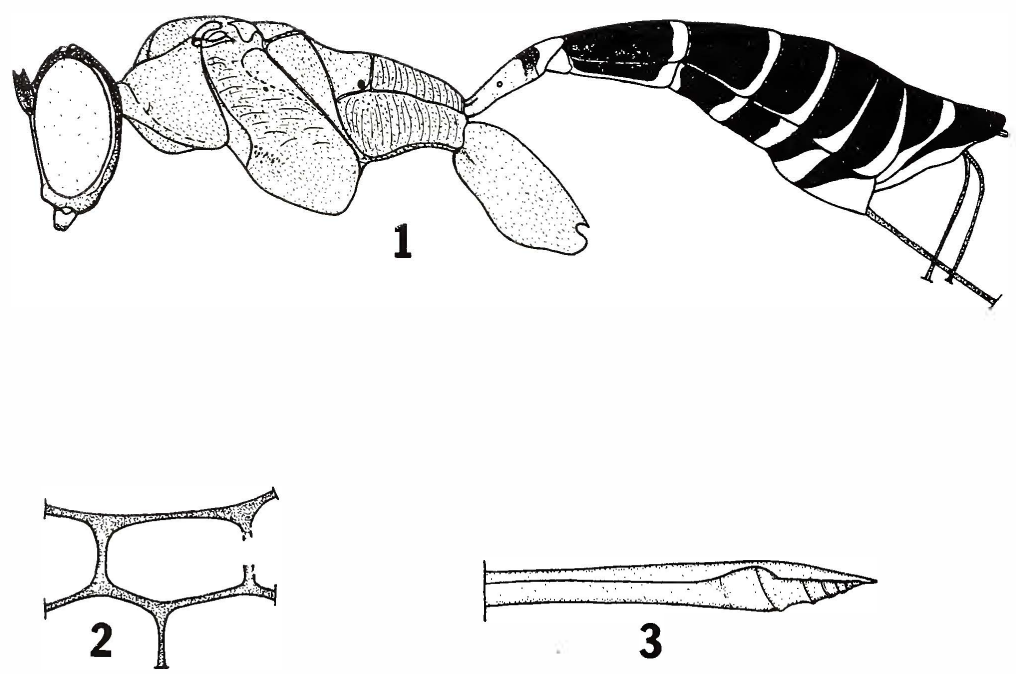

Fig. 1. Prosthoporus terani n. sp., female holotype. Lateral view of body showing color pattern and habitus.

Fig. 2. Prosthoporus terani n. sp., female holotype. Areolet.

Fig. 3. Prosthoporus terani n. sp., female holotype. Lateral view of apex of ovipositor.

tually will have to be redefined".

GENERIC NAME: Prosthoporus comes from the Greek adverb prosthen, "before, in front of", and the Greek noun poros, "pathway" or "pore". It was chosen in reference to the basal position of the first gastric spiracle in this genus.

\section{Prosthoporus terani new species}

(Figs. 1-3)

Holotype: female, Bolivia (Santa Cruz: General Saavedra, Estación Experimental Agrícola, November 1973, in Malaise Trap, C. C. Porter). (Gainesville).

FEMALE: Color: scape shining black with considerable brown staining below; pedicel black with brown on apex and below; flagellum black with a broad, ventrally incomplete white band that reaches from apical third of fourth through most of tenth segment and with some dull brownish below on eleventh to last 
segments; mandible white, grading through pale brown into black on apical third; head white on much of clypeus, much of face, and on a broad, ventrally interrupted orbital ring, with pale brown to orange brown on a large median occipital blotch behind ocellar triangle, on and between antennal sockets, on much of median field of face except above, in clypeal suture, medially on apex of clypeus, in much of malar space, on apical 1/3-1/2 of lower half of temple, and on most of postocciput, as well as with shining black on most of front, on much of vertex and occiput, and apically on upper half of temple; mesosoma shining pale red with some very obscure whitish staining, especially on scutellum, tegulae, subalarum, speculum, mesosternum, and apicad on lower metapleuron; first gastric tergite shining pale red except for a broad white crossband on its apical fifth and an even wider, somewhat irregular black area just preceeding the white band; the following tergites black with complete white apical bands on 2-7 and a medially interrupted white apical band on 8; fore and mid legs pale red to yellowish red on tibiae and tarsi, with a little dusky apicad on third tarsomere and with fourth and fifth tarsomeres blackish; hind leg with coxa, trochanter, trochantellus, and femur pale red, tibia yellowish red with slight dusky staining at base and becoming blackish on most of apical third, and tarsus white with blackish on about basal sixth of first segment, on apical half of fourth, and on all of fifth segment; wings hyaline.

Flagellum: segments 1-9 a little compressed with 10 and following somewhat thickened and then attenuate toward tip, the first segment 6.1 as long as deep at apex. Face: mat and finely granular with mostly well spaced, medium-sized shallow punctures. Temple: smooth and shining with small, sparse punctures.

Mesoscutum: smooth and polished with only a few tiny, scattered punctures that are best developed anteriad. Mesopleuron: prepectal carina reaches dorsad to about opposite upper 0.40 of hind margin of pronotum; no ridge on prepectus opposite lower hind corner of pronotum; surface smooth and shining on most of upper third, on speculum, and on the numerously but finely punctate prepectus but becoming mat with delicate irregularly longitudinal wrinkling on most of lower 2/3. Lower metapleuron: dully shining with very fine oblique wrinkling and micro-shagreening and scattered tiny, obscure punctures emitting moderately long but mostly well spaced setae. 
First gastric tergite: smooth and shining with faint micro-reticulation, especially on postpetiole, and some sparse, shallow, medium-sized punctures emitting well spaced setae. Second gastric tergite: shining with well developed micro-reticulation and some moderately numerous, large but very shallow punctures emitting well spaced setae. Succeeding tergites: 3 similar to 2; 4 and following with progressively smaller, more numerous punctures and denser, largely overlapping setae.

MALE: unknown.

TYPES: The unique holotype will be deposited in the Florida State Collection of Arthropods, Florida Department of Agriculture and Consumer Services, Gainesville, Florida.

HABITAT NOTES: The type locality is a patch of subtropical wet forest on an ecotone between the Chaco Húmedo and Selva Amazónica biotic provinces, which interdigitate near Santa Cruz, Bolivia where the drainage systems of the Paraná and Amazon Rivers come into close contact. This is a semi-evergreen plant community that dries out markedly during the winter months of July and August but which mainly is composed of hygrophile species, such as palms, cecropias, and giant-leaved epiphytic philodendrons.

SPECIFIC NAmE: For Ing. Oscar Terán of the Comisión Nacional del Estudio de la Caña y del Azucar, who made possible the Malaise trap survey at General Saavedra.

\section{REFERENCE}

TOW'NES, H.

1969. The Genera of Ichneumonidae, Part 2. Mem. Amer. Ent. Inst. 12: $1-537$. 


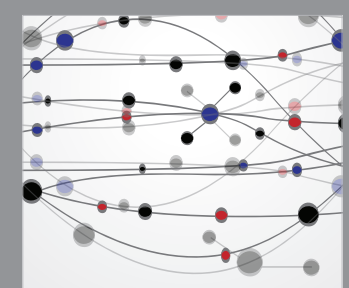

The Scientific World Journal
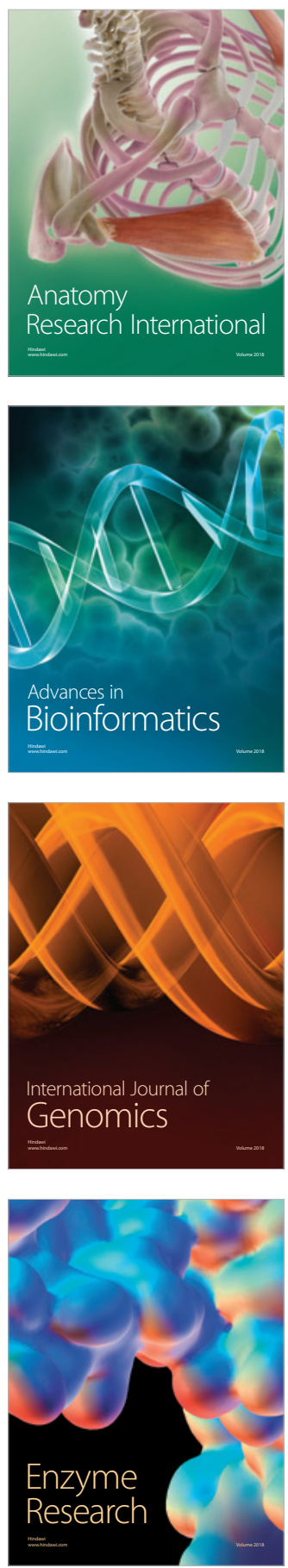
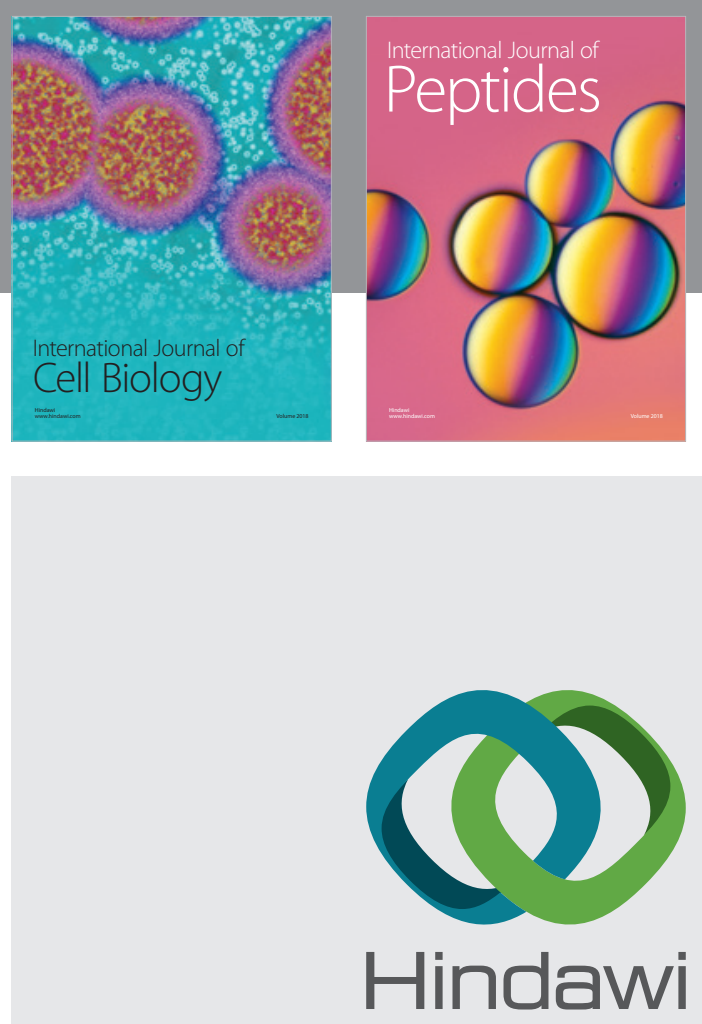

Submit your manuscripts at

www.hindawi.com
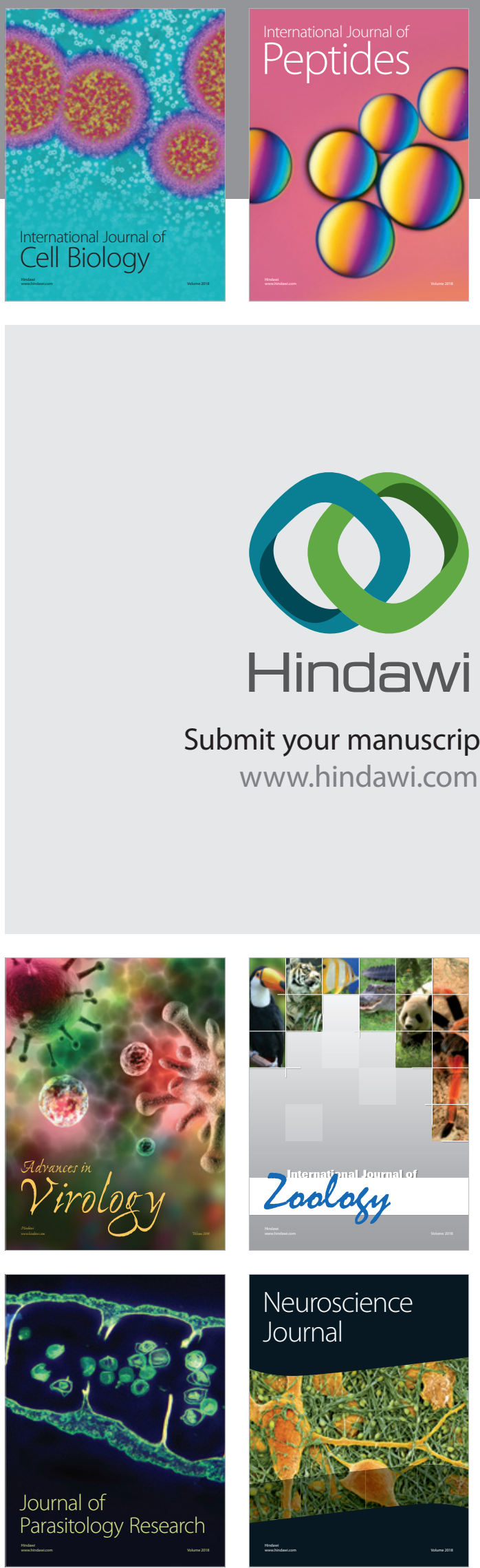
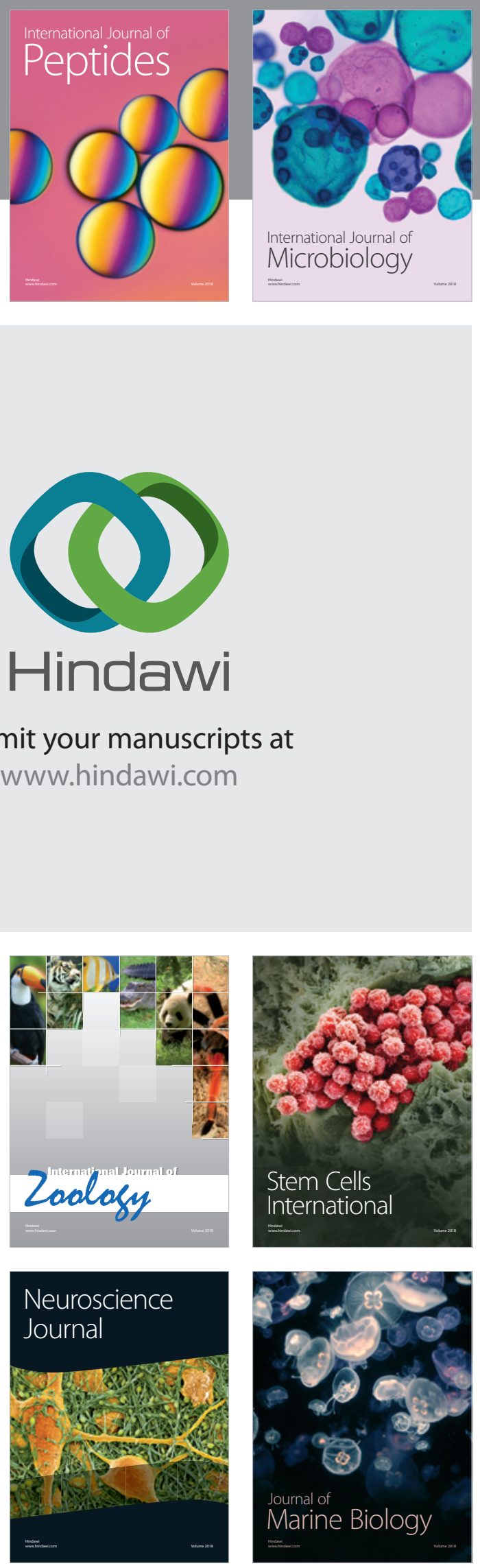
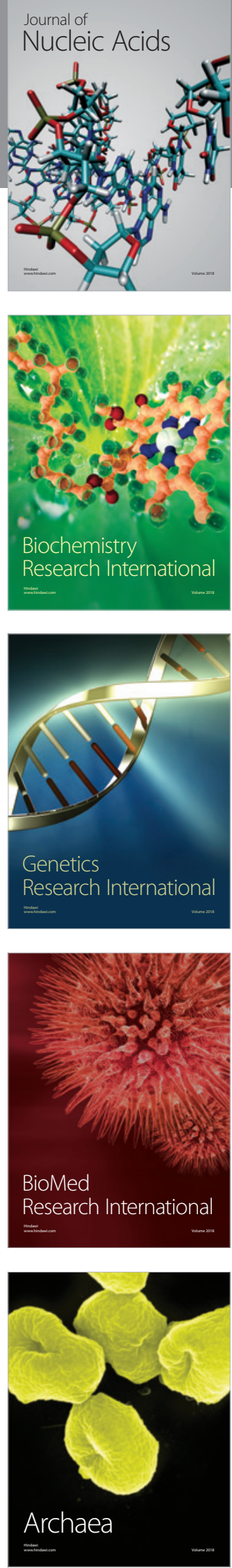